\title{
Assessment of Costs for Utilization of Amorphous Magnesite By-Products in Complex Production
}

\author{
Olga Vladimirovna Domozhirova \\ Department of Economics and organization of production \\ Belgorod State Technological University \\ named after V.G. Shoukhov \\ BSTU named after VG. Shoukhov \\ Belgorod, Russia \\ levaolga@mail.ru
}

\author{
Irina Alexandrovna Slabinskaya \\ Department of accounting and auditing. \\ Belgorod State Technological University \\ named after V.G. Shoukhov \\ BSTU named after VG. Shoukhov \\ Belgorod, Russia \\ iaslabinskaya@mail.ru
}

\begin{abstract}
The paper provides a brief summary of costs necessary to obtain nanosized magnesian powders when utilizing amorphous magnesite by-products. It also describes new methods ua accounting and allocation of common costs among products when processing and utilizing amorphous magnesite by-products in dynamic market conditions. Modern theoretical models of production cost management provide a fundamentally new approach to allocation of common costs between products obtained via processing and utilization of amorphous magnesite by-products and clarify methods of cost and result optimization in relation to processes of complex production. Besides, it lists the developed guidelines and practical recommendations that can also be used by enterprises of other industrial sectors with complex processing of raw materials.
\end{abstract}

Keywords - Costs in production facilities with complex processing of raw materials, management accounting, costs, cost optimization, amorphous magnesite, nanosized magnesian powder, by-product.

\section{INTRODUCTION}

Production facilities with complex processing of raw materials (chemical, petroleum, petrochemical, meat and dairy industries, polymetallic ore production and processing, etc.) were always and still are urgently facing the problem of allocation of common production costs between jointly obtained products [2].

The task is perceived complicated since during waste processing of amorphous magnesite by-products, it is impossible to ensure strict accounting of individual production costs of each jointly manufactured product. Having become legally and economically isolated and independent within the market, the enterprise as such defines its production plan, volume, structure and product range, thus following the requirements of market conditions and pricing. Under such circumstances, the problem of cost management and, especially, the problem of allocation of common costs between jointly manufactured products becomes particularly relevant [2].

Another main focus is the formation of a management accounting system based on allocation of common costs of the enterprise into constants, i.e. into products independent of the production volume per unit of time, and into variables, i.e. variable costs directly bound to the production volume per unit of time. The implementation of valid methods and accounting systems will make it possible not only to control and to reduce costs, to estimate production cost, but also to exercise efficient economic planning, control and regulation [7]. Such accounting system, unlike presently used accounting of full cost, allows solving a variety of problems with respect to costresult optimization and justification of different business management decisions on the basis of the analysis of correlation and interdependency between production output, cost and profit $[2,7]$.

\section{MAIN PART}

Various sectors of industry have complex production when several finished products are made in integrated technological conditions. At present, the share of complex production in a total amount of industrial output reaches 20\%. Further improvement of technology, enhancement of processing of complex raw materials and creation of waste-free technology productions will undoubtedly contribute to technical progress, concentration and combination of production, as well as fundamentally new complex productions [2].

Complex production exists in nonferrous and ferrous metal industry, construction materials industry, chemical, petrochemical and by-product coking industry, sawmilling, meat and dairy, food and other industries [7].

Some complex productions are characterized by complexity and variety of technological processes. In some productions, products are manufactured within one completed cycle (for example, synthetic alcohols); the others (for example, refining) - along with finished products, as a result of complex processing of feedstock, also make semi-products which are further processed by other productions.

Multiple manufacturing is a specific feature of production where a part of finished goods serves as either a raw material for another or the final product [2].

In response to the acceleration of technological development accompanied by an affluent reduction of product cycle life time, industrial enterprises and organizations face an urgent need for transition to new technology. Thus, as a rule, 
considerable investments in material and technical facilities, contributing to advanced technology solutions, impose certain responsibility on company management, thus forcing it to take relevant decisions [3].

Search of adequate criteria for the allocation of complex production costs from production to consumption goes across the final result.

If the sphere of production included search of criteria to evaluate by-products of complex production, then the sphere of consumption shall focus more on market criteria to evaluate all sold products irrespective of whether they constitute main or by-products. This leads to fundamental change in product cost calculation.

In complex production, when there is no relation between cost and attributes of their allocation among manufactured products when determining prices, there is a need to solve the main task, i.e. to define the ratio of market prices among separate products of complex production, and then the costs of such products instead of studying methods of cost allocation as it is recommended by industry-based instructions, currently implemented in reality.

So, the main objective of cost planning within complex production is to define the ratio of prices between separate jointly manufactured products. Let us consider what forms the basis for such ratios in the sphere of consumption.

Consumers are more interested in the end-user performance and price of a product rather than in costs of production. The end-user performance of products represents the gradable system of physical, chemical, geometrical, organoleptic and other indicators specified in standard regulations which describe the utility of a particular product being consumed and determine their use value.

When comparing various utility models there is a need to identify two big product groups: consumer goods and means of production. The lack of utility units of measurement does not mean that the utility of different products in general are incomparable. With regard to consumer goods they are comparable in terms of their preference, i.e. choice. Different persons can have various choices, but nevertheless it will be made, and while making a choice a consumer will compare the most unexpected benefits of a product.

The situation is slightly different with industrial goods, in particular with materials and supply being a subject of our study. Here, the consumer is not a certain individual, but a team, and, the decision on the choice of either goods is supported by cost estimates. Thus, the assessment of end-user performance of either industrial goods is less subjective compared to the assessment of the same properties of consumer goods, and is generally perceived as a participatory or public assessment.

The consumer of industrial goods, when deciding to buy a product, undoubtedly, estimates the result of its utilization as intended and included in the use value. Such assessment considers the whole set of consumer properties of a product, their influence on the final result in specific technological conditions [6].

Thus, only similar, in terms of their purpose products, may be evaluated through comparison of their consumer properties. Therefore, only identical or similar consumer properties can be compared. In petrochemical processes, jointly manufactured products differ a lot in their consumer properties, and, in turn, it makes them entirely noninterchangeable.

Through direct comparison of consumer properties it is almost impossible to determine which product of complex production is more useful. However, in reality, consumer properties are primarily considered by a consumer. Numerous the so-called 'consensus' meetings between manufacturers and consumers of production on the approval of standards and regulations are devoted to scrupulous discussion of each indicator within end-user performance. Such biased interest of a consumer to end-user performance of a product is natural since the use of a product with the best consumer properties leads either to the decrease in specific consumption rates, or to the improvement of consumer properties of final products with all positive changes that it implies as a result of a business activity.

However, the achievement of preconditioned consumer properties of a product is bound to certain expenses that the product manufacturer is bearing. If consumer requirements to consumer properties of a product rise, the manufacturer has to meet such advanced requirements to a product in order not to lose or even to expand its market share.

There are multiple ways to improve consumer properties of a product. With other things being equal (i.e. if there are no revolutionary breakthroughs in technology leading to a sharp reduction of production costs), all these ways to improve consumer properties of a product are inevitably connected with the increase in operational expenditures.

At the same time, the market prices of products with advanced consumer properties are higher the prices for standard goods. This is commonly known and does not deserve particular attention if not connected to production. However, it seems that the prices and production costs are in close connection and interdependence.

The final and specific result of product application with any consumer properties represents the economic effect gained by the consumer, and the higher it is, the more useful the product is. For the consumer, the economic effect as such serves the criterion of utility assessment of various products in use. A specific cost expression of such assessment is the price which the consumer pays upon the purchase of a product. If the offer price is so high that the consumer when using a product will not gain the expected economic effect, he will not buy this product. On the other hand, if the demand price is so low that the manufacturer when selling a product will not get the expected profit, he will refuse to manufacture this product. 
Finally, there should be a balance between supply and demand for a specific product when both the manufacturer and the consumer are satisfied with its price. Since numerous manufacturers and consumers of a product participate in establishing this balanced price in the market, it is possible to say that such price is proportional to average socially necessary cost of production.

Th.E. Klipstein in his book The Study on Alternatives in Accounting (Leipzig, 1781) demonstrated by an example of metallurgical industry how direct costs should be split into separate phases (limits): extracting production, coal, slag processing, melting, forging, while overhead costs shall be directly bound to the profit for the period [13].

I.C. Courcell-Seneuil in his Theory and Practice of Entrepreneurship in Agriculture, Workmanship and Trade (Stuttgart, 1869) suggested dividing costs into special and common, where special costs only changed to the same extent as the volume of delivered goods did, and common costs remained stable or practically did not change within existing bounds [12].

These logical conclusions concerning complex production allow saying that if the market price of any jointly manufactured product exceeds the price of other product, then the costs of their production shall fit the same proportion.

Algebraically, such proportionality can be expressed as follows:

$$
\frac{c_{1}}{z_{1}}=\frac{c_{2}}{z_{2}}=\frac{c_{3}}{z_{3}}=\frac{\sum_{i=1}^{n} c_{i} p_{i}}{\sum_{i=1}^{n} z_{i} p_{i}}
$$

where $\quad c_{i}$ - price of $i$-product;

$z_{i}-$ costs for production of $i$ - product;

$p_{i}$ - production volume of $i$-product;

$i$ - item number of a product $(i=1,2,3, \ldots, \mathrm{n})$.

\section{METHODS}

Taking into account the specified conclusions, one can develop a new approach to cost formation within complex production industry.

Let us consider fundamentals and guidelines of waste treatment technology applied for amorphous magnesite byproducts

Let us use the following terms with corresponding definitions:

Magnesite is a mineral, a natural magnesium carbonate, its theoretical structure is $47.62 \% \mathrm{MgO}$ and $52.38 \% \mathrm{CO}_{2}$. The rock consisting mainly of magnesite mineral $\mathrm{MgCO}_{3}$ decaying at a temperature of $650-670{ }^{\circ} \mathrm{C}$ into magnesium oxide and carbon dioxide: $\mathrm{MgCO}_{3}-\mathrm{MgO}+\mathrm{CO}_{2}$.
Amorphous magnesite represents porcelaneous mass mostly having snow-white color which becomes yellowish, brown or gray when mixed with impurities. It is usually confined in serpentine and consists of the finest magnesium carbonate $\left(\mathrm{MgCO}_{3}\right)$ crystals impregnated with amorphous silicic acid in the form of an opal.

Wastes of amorphous magnesite by-products represent debris consisting of amorphous magnesite and serpentine less than $20 \mathrm{~mm}$ in size with amorphous magnesite content from 30 to $50 \%$.

In industry, magnesite also means carbonate rocks with crystal or amorphous structure mainly consisting of a magnesite mineral with admixed hydromagnesite, dolomite, calcite, talc, chlorite, clay and carbon matter, iron oxides and other minerals.

Amorphous magnesite by-product wastes in production are understood as something uniform until a certain moment, i.e. a primary separation point. After passing this stage, various output products, as well as a primary separation point, are defined, i.e. the process of primary processing of amorphous magnesite by-product waste serves the center that defines costs of all final products [5].

In turn, many products obtained at a primary separation point are exposed to additional processing at subsequent stages of production (processing). This may include processes of subsequent separation, treatment, mixture, etc.

Each stage (processing) of production is the center of formation of total production costs.

The best way of amorphous magnesite by-product waste processing is a set of technological solutions and operational actions allowing one to gradually recover magnesite concentrate from a crushed ore via magnetic separation to receive magnesium nitrate via nitric acid leaching of serpentine-magnesite residue and to obtain nanosized magnesian high-purity powders through intensive crushing and thermal decomposition of salts.

In general, the technology of amorphous magnesite byproduct processing consists of three stages which can be presented as the scheme shown in Fig. 1:

1. phasic crushing, classification and magnetic separation of amorphous magnesite by-product wastes;

2. leaching of serpentine-magnesite residue after magnetic separation, magnesian salts production;

3. primary grinding, a high-thin dispergation of magnesite concentrate and magnesian salts with subsequent hightemperature treatment of dispersed powder [5].

Crude ore phasic crushing is extremely important and takes into account differences in strength properties of mineral associations and conditions for complete fracture of calcium carbonate released grains and serpentine due to their mastication through mechanisms of crushing and transportation. 
Tailingsamorphousmagnesite
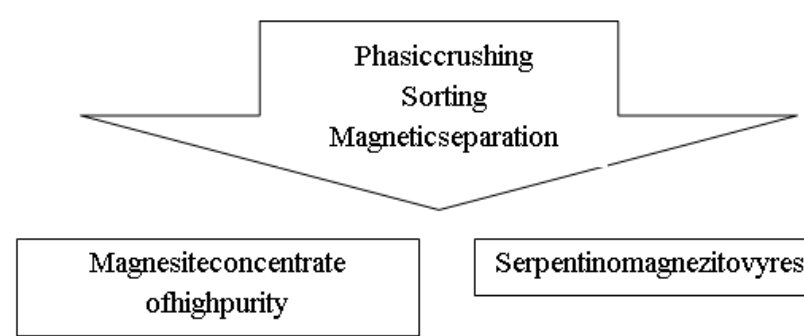

Serpentinomagnezitovyresidue
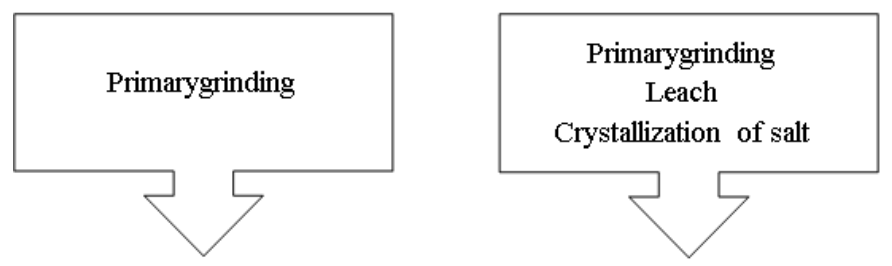

High of fine grinding

Roasting

The nano-sized powders of high purity

Fig. 1. Waste treatment technology of amorphous magnesite by-products

The received crushed product is dispersed according to the grain size grade. The class less than $0.25 \mathrm{~mm}$ is considered a residue and is integrated with finely dispersed material depositing in air cyclones. The produced compound is used as raw materials for the production of magnesite-serpentine bonding material [5].

The classes of 2.0-1 mm, 1-0.25 mm are sent for twophasic dry magnetic separation as a result of which magnesite concentrate (its output makes > 80 rel. \% with $\mathrm{MgCO} 395$ content of $98 \%$ ) and serpentine-magnesite residue are produced.

Magnesium nitrate produced as a result of the leaching of serpentine-magnesite residue by nitric acid, preliminary crushed to the grain size of less than 100 microns, is crystallized and supplied as a solid substance to highly fine grinding dispersant. The air-dust compound is cleared through the combustion chamber with further thermal decomposition of salt into nanosized powder of magnesium oxide which precipitates in a cyclone [5].

The primary separation considers all costs, including costs for initial raw materials - amorphous magnesite by-product wastes and costs of processing (purchased materials, catalytic agents, reagents, self-produced semi-finished products, energy consumption and other variable expenses directly bound to manufactured products) [2].

The following stages do not consider the cost of initial raw materials - amorphous magnesite by-product wastes, but only consider additional costs of processing.
Such order of cost accounting allows one, on the one hand, to avoid double counting of cost for initial raw materials, and, on the other hand, to consider all additional costs of product finishing during primary separation to their final commodity form.

The general approach to cost allocation between jointly manufactured products is as follows:

Costs are classified into variable and fixed costs (further variables and fixed costs). Separate account of costs is ensured according to established classification.

Common variable costs are distributed between products. At the same time, as it was already mentioned, at a primary separation point the variables are combined with the cost for initial raw materials, and at subsequent processing stages only variable costs for processing.

Sold products are considered as the subject of cost allocation.

All sold products obtained through complex production are considered the main products, i.e. division of products into main and by-products is excluded.

The common variable cost of primary processing of initial raw materials (including the cost of initial raw materials) are allocated between all sold products in proportion similar to the sales volumes of these products minus the costs of their processing into subsequent stages (after separation point) [2].

To define the full cost of products, fixed costs are also allocated; however such calculation is made after variable costs are allocated.

Since the methodology of fixed cost allocation is similar to that of variable costs, for simplicity of calculation it is possible to allocate fixed costs between products proportionally to already calculated variable costs. At the same time, fixed costs in a primary separation point cover all products, and during subsequent stages - only the products obtained as a result of processing.

As it was already said, costs that belong to all final products are formed at a primary separation point. The formula () shows that in this point the share of common costs for every specific product $\left(d_{i}\right)$ can be defined as follows:

$$
d_{i}=\frac{c_{i} p_{i}}{\sum_{i=1}^{n} c_{i} p_{i}}
$$

Therefore, with known common costs in a primary separation point of initial raw materials, the production costs for every specific product are defined according to formula: $\mathrm{Z}$

$$
\mathrm{Z}_{i}=\frac{c_{i} p_{i}}{\sum_{i=1}^{n} c_{i} p_{i}} \cdot \mathrm{Z}_{o},
$$

where $Z_{i}$ - costs for total volume of sold i-product; 
$Z_{o}$ - common costs for all sold products in a primary separation point of initial raw materials.

However, such approach to common cost allocation would be correct if after a primary separation point the products were not exposed to further processing. In fact, as it was already mentioned, the majority of obtained products at a primary separation point of initial raw materials are exposed to additional processing at subsequent stages, and due to this, costs for their production increase. But such costs are not related to the whole bulk of products, but rather to specific products exposed to additional processing.

When costs for processing after passing a primary separation point are known, the share of common costs for primary processing of initial raw materials covering specific product is defined as follows:

$$
d_{i}=\frac{c_{i} p_{i}-\mathrm{Z}_{i j}}{\sum_{i=1}^{n} c_{i} p_{i}-\sum_{j=1}^{m} \mathrm{Z}_{i j}}
$$

where $Z_{i j}-$ cost rate for processing of $\mathrm{i}$-product at $\mathrm{j}$-stage (center of cost formation) after a primary separation point of initial raw materials;

$j$-item number of the process stage $(\mathrm{j}=1,2,3, \ldots, \mathrm{m})$.

Hence, aggregate variable costs of production of a specific product will be equal:

$$
\mathrm{Z}_{p i}=\frac{c_{i} p_{i}-\mathrm{Z}_{i j}}{\sum_{i=1}^{n} c_{i} p_{i}-\sum_{j=1}^{m} \mathrm{Z}_{i j}} \cdot \mathrm{Z}_{o}+\mathrm{Z}_{i j}
$$

where $Z_{p i}$ - variable costs for production of i-product,

and variable costs per unit of i-product:

$$
\mathrm{Z}_{n i}=\left[\frac{c_{i} p_{i}-\mathrm{Z}_{i j}}{\sum_{i=1}^{n} c_{i} p_{i}-\sum_{j=1}^{m} \mathrm{Z}_{i j}} \cdot \mathrm{Z}_{o}+\mathrm{Z}_{i j}\right]: p_{i},
$$

where $z_{p i}-$ variable costs per unit of i-product.

\section{CONCLUSIONS}

Opponents of the suggested method may indicate apparent 'perversity' of the approach to cost allocation among products of complex production when prices defined by costs, i.e. by unknown quantity, are used as indicators of cost allocation.

However, costs of production did and will serve as the basis for price calculation, and the higher or lower the costs per product unit is, the higher or lower the price will be. Certainly, the size of the profit included in the price is not anymore imposed by market conditions, and depends on many factors.
In general, for all similar goods offered and demanded in the market, the level of product price will depend on the average costs of its production. The manufacturers producing goods at lower cost will gain big profit and vice versa.

In market conditions, the process of 'approval' of costs and prices always takes place against the actual purchase, and this process is continuous and constant. From the mathematical point of view, it is possible to talk about infinite iteration within the system of "costs $\Leftrightarrow$ prices" through the system of "supply $\Leftrightarrow$ demand" where the problem of a "vicious circle' loses its practical relevance.

Conclusions. Hence, in the authors' opinion, for complex production it is possible to draw the following logical conclusions:

1) both the total amount of market prices for the whole variety of products and the individual costs of each separate product of complex production have to reflect actual individual prices for the whole set of such products;

2) common costs of complex products at a primary separation point are allocated between them in proportion to their market value taking into account availability of goods.

These conclusions form the basis for the suggested approach to cost formation with regard to nanosized magnesian powders during amorphous magnesite by-product waste utilization.

The authors believe that the suggested approach can be used in the costing of products and other complex production fields.

\section{Acknowledgments}

The study is implemented under the Flagship University Development Program of Belgorod State Technological University named after V.G. Shukhov.

\section{References}

[1] O.B. Benderskaya, I.A. Slabinskaya, L.N. Kravchenko, "Economic analysis: manual," Belgorod: Publishing House of BSTU named after V.G. Shukhov, 2016. pp. 488.

[2] O.V. Domozhirova, "Current problems of costing for oil products in modern market conditions," Belgorod: Publishing House of BSTU named after V.G. Shukhov, 2014, pp. 116.

[3] Yu.A. Doroshenko and I.V. Somina, "Use of dynamic programming in designing the innovative and technological strategy of an enterprise," Bulletin of BSTU named after V.G. Shukhov, v. 6, 2014, pp. 147-149.

[4] Review of magnesian raw materials market (magnesite and brucite) and magnesite powders in CIS: v. 3 enlarged and arranged," M.: LLC RG Infomine, 2011. pp. 137.

[5] Report on applied research \# state registration 114111740004. Development of new technology and equipment to obtain nanosized magnesian powders during recycling of amorphous magnesite for different industries. Federal Target Program "R\&D forpriority areas of the development of S\&T complex of Russia for 2014-2020", 2015.

[6] A.A. Rudychev, A.Yu. Lychev, "Enterprise sustainability assessment methods," Bulletin of BSTU named after V.G. Shukhov," v.3, 2014, pp. $120-124$. 
[7] A.A. Rudychev, I.A. Slabinskaya, O.V. Domozhirova and S.P. Gavrilovskaya, "Problems of cost optimization in enterprises with rational utilization of feedstock," Belgorod: Publishing House of BSTU named after V.G. Shukhov, 2011, p 143.

[8] E.D. Shchetinina, M.S. Starikova, "Control of expenses of innovative activity as an element of business strategy," Scientific and theoretical journal: Bulletin of BSTU named after V.G. Shukhov, v.1, 2015, pp. 92 -97 .

[9] V. Aggelatou, E.I.P. Drosos, Th. Zampetakis, A. Meidani, S Dambitzias, N. Arvanitidis, "Upgrading mining waste to develop added value final products," $6^{\text {th }}$ International Conference Sustainable Development in the Minerals Industry SDIMI, 2013

[10] Y. Belrhiti, M. Huger, T. Chotard, "Characterization of the Mechanical Behavior of Magnesia Spinel Refractories Using Image Correlation," Int. J. Appl. Ceram. Technol., vol. 11(6), 2014, pp. 1025-1029.

[11] G. Binal, N. Ay, "Utilization of magnesite host rocks in wall tile," Journal of the australian ceramic society, vol. 51, 2015, 1. pp. 1-7.
[12] I. C. Courcell-Seneuil, "Theorie und Praxis des Gescaftspetriebes in Ackerbau,"Gewerbe und Handel. Stutgart, 1869, p. 208.

[13] Th. E. Klipstein, "Lehre von der Auseinandersetzung im Rechnungswesen," Leipzig, 1781, p. 350.

[14] S. Mukhopadhyay, A.K. Chattopadhyay, "Effect of MgO Grain Size on Thermal Expansion Behavior of Alumina-Magnesia-Carbon Refractory," Int. J. Appl. Ceram. Technol., vo. 11(6), 2014, pp. 1012 1019.

[15] C.V. Parente, L.H. Ronchi, A.N. Sial, J.J. Guillou, M.H. Arthaud, K. Fuzikawa, I.U.V. VerÍssimo, "Geology and geochemistry of paleoproterozoic magnesite deposits $(-1.8 \mathrm{Ga})$, state of ceará, northeastern brazil,"Carbonates and Evaporites, vol. 19, 2004, 1. pp. 2850.

[16] K.R. Wilkerson, J.D. Smith, "Metastability in the $\mathrm{MgAl}_{2} \mathrm{O}_{4}-\mathrm{Al}_{2} \mathrm{O}_{3}$ System," Int. J. Appl. Ceram. Technol., vol. 11(6), 2014, pp. 1020 1024. 